\title{
Controlling Your Impulses: Electrical Stimulation of the Human Supplementary Motor Complex Prevents Impulsive Errors
}

\author{
Laure Spieser, ${ }^{1}$ Wery van den Wildenberg, ${ }^{2,3}$ Thierry Hasbroucq, ${ }^{1}$ K. Richard Ridderinkhof,,${ }^{2,3}$ and Borís Burle ${ }^{1}$ \\ ${ }^{1}$ Aix-Marseille Université, Centre National de la Recherche Scientifique, LNC Unité Mixte de Recherche 7291, 13331 Marseille Cedex 3, France, ${ }^{2}$ Amsterdam \\ Center for the study of Adaptive Control in Brain and Behavior (Acacia), University of Amsterdam, 1018 XA Amsterdam, the Netherlands, and ${ }^{3}$ Amsterdam \\ Brain \& Cognition, University of Amsterdam, 1018 WB Amsterdam, the Netherlands
}

To err is human. However, an inappropriate urge does not always result in error. Impulsive errors thus entail both a motor system capture by an urge to act and a failed inhibition of that impulse. Here we show that neuromodulatory electrical stimulation of the supplementary motor complex in healthy humans leaves action urges unchanged but prevents them from turning into overt errors. Subjects performed a choice reaction-time task known to trigger impulsive responses, leading to fast errors that can be revealed by analyzing accuracy as a function of poststimulus time. Yet, such fast errors are only the tip of the iceberg: electromyography (EMG) revealed fast subthreshold muscle activation in the incorrect response hand in an even larger proportion of overtly correct trials, revealing covert response impulses not discernible in overt behavior. Analyzing both overt and covert response tendencies enables to gauge the ability to prevent these incorrect impulses from turning into overt action errors. Hyperpolarizing the supplementary motor complex using transcranial direct current stimulation (tDCS) preserves action impulses but prevents their behavioral expression. This new combination of detailed behavioral, EMG, and tDCS techniques clarifies the neurophysiology of impulse control, and may point to avenues for improving impulse control deficits in various neurologic and psychiatric disorders.

Key words: conflict task; executive control; impulse control; partial errors; pre-SMA/SMA; tDCS

\section{Introduction}

Both environmental factors and internal states may trigger impulsive but inappropriate action tendencies. When such impulses produce overt erroneous behavior, consequences can be dramatic, in terms of traffic or work accidents, or social relationships; psychopathology frequently involves dysfunctional action impulsivity (Chamberlain and Sahakian, 2007). In the laboratory, the ability to exert control over impulsive but inappropriate action tendencies is typically studied using choice reaction-time tasks. In such tasks, analyzing accuracy as a function of poststimulus time typically shows that the fastest responses are the most error-prone, revealing fast impulsive responses. In the stimulus-response compatibility (SRC) task (Fitts and Deininger,

\footnotetext{
Received April 22, 2014; revised Dec. 27, 2014; accepted Jan. 2, 2015.

Author contributions: L.S., W.v.d.W., T.H., K.R.R., and B.B. designed research; L.S. and W.v.d.W. performed research; L.S. and B.B. analyzed data; L.S., W.v.d.W., T.H., K.R.R., and B.B. wrote the paper.

The authors declare no competing financial interests.

This work was supported by the European Research Council under a European Community Seventh Framework Program Grant (FP7/2007-2013 Grant Agreement \#241077). We thank Jasper Wijnen and Marcus Spaan for their technical help, and Thomas Gladwin and Frederik Verbruggen for helpful exchanges. We additionally thank anonymous reviewers for their helpful comments.

Correspondence should be addressed to either of the following: Laure Spieser, Department of Psychology, City University London, Northampton Square, London, EC1V OHB, UK, E-mail: Laure.Spieser@city.ac.uk; or Borís Burle, Laboratoire de Neurosciences Cognitives, Aix-Marseille Université, CNRS, UMR 7291, 3, Place Victor Hugo Case C, Site Saint Charles, 13331 Marseille cedex 3, France. E-mail: boris.burle@univ-amu.fr.

DOI:10.1523/JNEUROSCI.1642-14.2015

Copyright $\odot 2015$ the authors $\quad 0270-6474 / 15 / 333010-06 \$ 15.00 / 0$
}

1954), the correct response is designated by stimulus location, either according to a spatially compatible (e.g., press right to a circle presented on the right) or an incompatible mapping rule (press left to a right circle; Fig. 1a). Activating the response ipsilateral to the stimulus constitutes a prepotent action tendency, hence leading to impulsive erroneous actions, especially in incompatible trials in which fast errors are triggered by the incompatible stimulus position. Yet, such fast overt errors are only the tip of the iceberg. Indeed, electromyography (EMG) has revealed initial subthreshold muscle activation of the incorrect response hand in 15 to $25 \%$ of overtly correct trials (for overview, see van den Wildenberg et al., 2010). Such "partial errors" expose covert response impulses that are not discernible in overt behavior (Fig. $1 b$ ) and can be used to gauge the expression of covert error impulses, as well as the ability to prevent these impulses from turning into overt action errors.

The implication of the supplementary motor complex [SMC, including the supplementary motor area (SMA) and the preSMA] in the control over such unwanted actions has been reported by several studies (or studies using spatial conflict tasks, see Forstmann et al., 2008b; Herz et al., 2014). However, whether SMC prevents stimulus-triggered response activations or blocks their behavioral expression, i.e., refrains them from turning into impulsive overt responses, is still unknown. We addressed this critical question by modulating SMC activity using transcranial direct current stimulation (tDCS), a noninvasive brain stimula- 
a Compatible

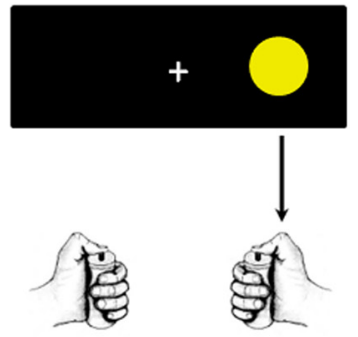

Incompatible

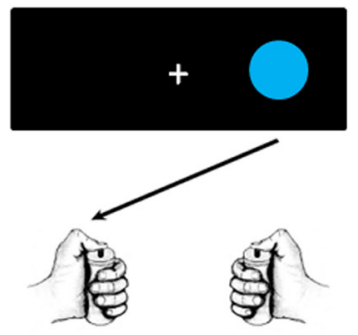

b

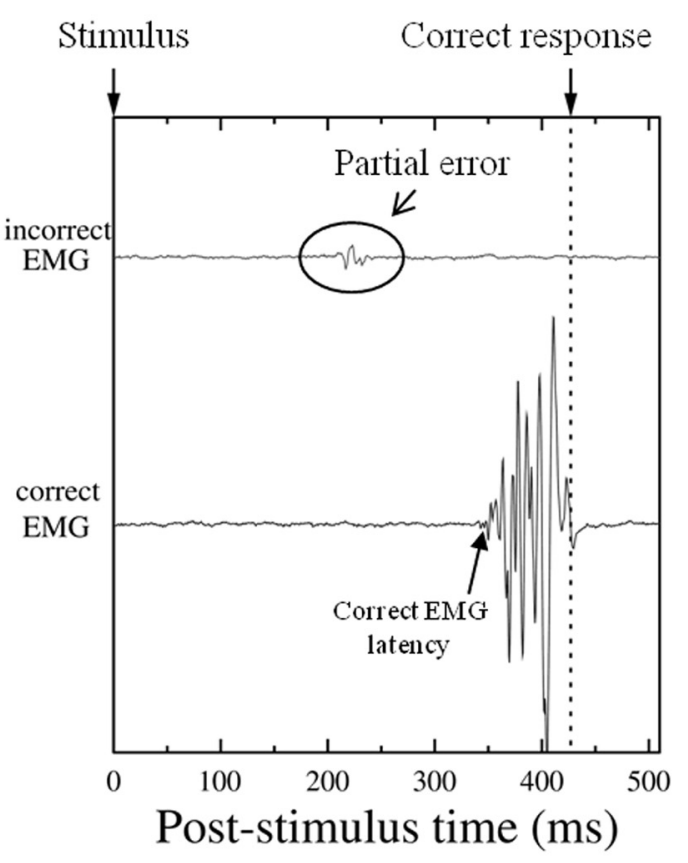

C

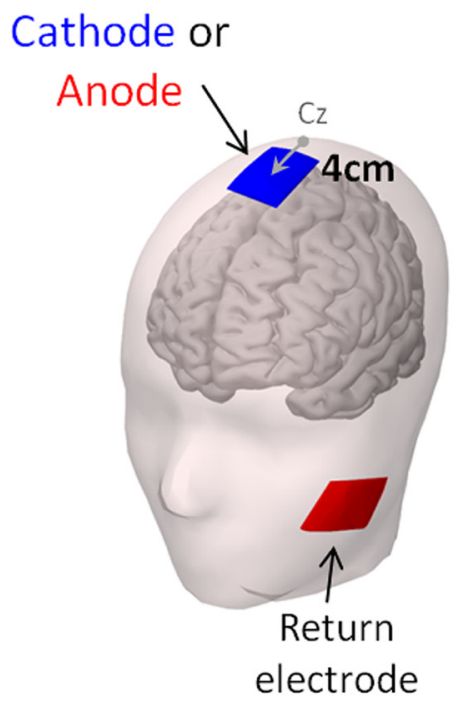

d

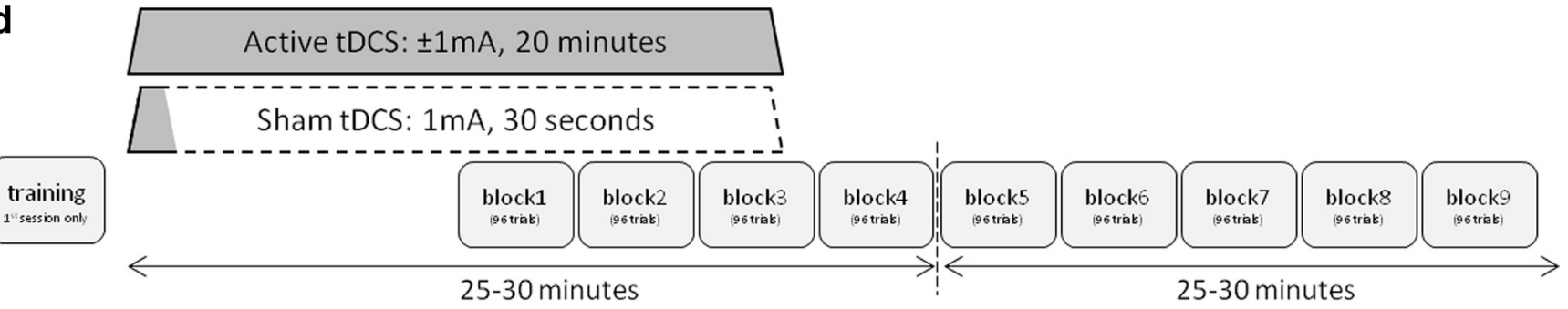

Figure 1. Experimental procedures. $a$, Depending on stimulus color (yellow or blue), subjects responded on the same side (compatible trial) or the side opposite to the circle location (incompatible trial). $\boldsymbol{b}$, In a partial error trial, an incorrect subthreshold EMG burst (top trace) preceded the EMG activity of the correct response hand (bottom trace). $\boldsymbol{c}$, The active tDCS electrode was centered $4 \mathrm{~cm}$ in front of (Z; the return electrode was on the left cheek. $\boldsymbol{d}$, Stimulation was applied over 20 min (active tDCS) or only $30 \mathrm{~s}$ (sham). Subjects always started to perform the task 10 min after tDCS has been turned on. In the first behavioral session, the subject practiced the task.

tion technique, while subjects performed an SRC task. SMC activity was modulated using either cathodal (inducing neuron hyperpolarization) or anodal tDCS (causing depolarization; Nitsche et al., 2008). We analyzed impulsive partial and overt errors separately. Processes linked to covert response impulses, revealed by partial errors, appeared to be independent of SMC excitability, whereas processes related to the control of those impulses were shown to be affected by SMC modulation.

\section{Materials and Methods}

\section{Participants}

Twenty-four healthy subjects (18 females; two left-handed; age range, 18-34 years; mean, 22 years) participated in this study. None of them took any medication, nor presented any contraindication to tDCS. All had normal or corrected-to-normal vision. All gave informed consent and the study (conducted in full compliance with relevant legislation and institutional guidelines) was approved by the ethics review board of the University of Amsterdam. Subjects were recruited from the local student population and received either course credits or financial compensation.

\section{tDCS procedure}

tDCS was applied using a neuroConn DC-stimulator Plus connected to two rubber electrodes $(5 \times 7 \mathrm{~cm}$ each). The active electrode, targeting the pre-SMA, was centered $4 \mathrm{~cm}$ anterior to $\mathrm{Cz}$ (Fig. 1c), an appropriate location to stimulate this area (Rushworth et al., 2002; Mars et al., 2009).
However, even though the pre-SMA was the targeted area and hence received the strongest stimulation, activity of neighboring areas, such as the SMA (just caudal to the pre-SMA), might also have been modulated. For this reason, we refer to the SMC, which includes the pre-SMA and SMA (Nachev et al., 2008). The return electrode was placed on the left cheek (Fig. 1c). EEG paste (Ten20 paste) facilitated the contact between skin and tDCS electrodes.

A current of $-1 \mathrm{~mA}$ (cathodal stimulation) or $+1 \mathrm{~mA}$ (anodal stimulation) was applied over $20 \mathrm{~min}$ (duration of the rising and decreasing ramps, $8 \mathrm{~s}$ ). In the sham condition, a current of $1 \mathrm{~mA}$ was applied over $30 \mathrm{~s}$ (Fig. 1d) so that the participants experienced the same itching sensation as in actual stimulation. Each subject received the three stimulation conditions in different sessions separated by $\geq 48 \mathrm{~h}$. Session order was counterbalanced between subjects.

To maximize the amount of trials collected in each session, subjects started to perform the task $10 \mathrm{~min}$ after stimulation started. The tDCS stimulator turned off automatically $10 \mathrm{~min}$ later. The same procedure was used for the sham condition, although in this case the stimulator turned off after $30 \mathrm{~s}$. Such sham stimulation is known to be indistinguishable from active stimulation conditions by participants (Gandiga et al., 2006), which was confirmed here by postexperiment debriefing. Participants were hence blind to the tDCS condition. Also note that, although the experimenter was not naive regarding the applied stimulation, task instructions, given only at the first session, were exactly the same for all conditions. 
Experimental setup and task

The subject sat at $\sim 1.20 \mathrm{~m}$ in front of a screen presenting the stimuli. She or he positioned the distal phalanx of each thumb on response buttons, placed on the top of two plastic cylinders $(3 \mathrm{~cm}$ in diameter, $12 \mathrm{~cm}$ in height) fixed vertically on the table (Fig. 1a). Trials began by the appearance of a central fixation cross, followed $500 \mathrm{~ms}$ later by a yellow or a blue circle appearing either on the left or on the right (visual angle $1.8^{\circ}$ to stimulus center). Depending on the circle color, subjects responded with the hand corresponding to circle location (compatible trial) or opposite to circle location (incompatible trial; Fig. 1a). The two colors (yellow vs blue) and the two locations (left vs right) were equiprobable and pseudorandomized (first-order compatibility sequences were counterbalanced using Mix software; van Casteren and Davis, 2006). The experiment was performed using Presentation software (www.neurobs.com). Half of the subjects issued a spatially compatible response for yellow circles and a spatially incompatible response for blue circles. Mapping was reversed for the other half of the participants. If no response was given after $1 \mathrm{~s}$, the stimulus was turned off and the next trial began $1 \mathrm{~s}$ later. In each session, subjects performed nine blocks of 96 trials: three blocks were performed during $\mathrm{tDCS}$, and six blocks after tDCS (Fig. 1d). All trials were completed within 40 min after stimulation ended.

\section{Data recording and processing}

Trials were excluded if reaction time was $<100 \mathrm{~ms}$ or $>1000 \mathrm{~ms}(<2.5 \%$ of the trials). The effect of tDCS and compatibility was investigated by two-way ANOVAs for repeated measures complemented with planned comparisons for specific contrasts. Proportions were normalized using arc-sine transformation before analyses (Winer, 1971).

$E M G$. EMG activity of the flexor pollicis brevis of each hand was recorded bipolarly using preamplified Ag/AgCl electrodes (Flat active electrodes, BioSemi; sampling rate, $2048 \mathrm{~Hz}$ ). EMG signal was then high-pass filtered $(10 \mathrm{~Hz})$ and rectified. Finally, using automatic detection first (implemented in BrainVision Analyzer 2, Brain Products), followed by a manual verification, the onset of each EMG burst was marked. During this procedure, the experimenter was not aware of the type of trial (compatible or incompatible, correct or error) that she was marking, but was not naive regarding the tDCS condition. Note that it is nonetheless unlikely that this affected the marking procedure as similar partial error latencies, rates, and distributions were obtained for all tDCS conditions.

The presence of tonic muscular activity prevents accurate detection of partial errors. Hence, special care has to be taken before and during EMG experiments to reduce continuous muscular activity (changing hands/ arms position to allow complete muscle relaxation, repositioning electrodes, etc.). Given that tDCS affords a limited time window for data collection, it was not always possible to spend the time necessary to ensure an optimal EMG signal. Furthermore, because of the withinsubjects design, the presence of such tonic activity in $\geq 1$ session led to the complete exclusion of the subject. For this reason, 6 of 24 participants had to be excluded from analyses.

For the remaining 18 subjects, EMG trials were classified in one of the four following categories: correct trials were classified as "pure-correct" when only the EMG activity associated with the correct response was present, and as "partial error" when a weak EMG activation, too small to trigger an overt response, occurred in the incorrect hand before the correct EMG burst (Fig. 1b); overt error trials showing only incorrect EMG activity associated with the incorrect response were defined as "pureincorrect"; trials containing other sequences of EMG were labeled "other" and occurred in $34.6 \%$ of trials. This relatively high percentage (compared with previous reports; Burle et al., 2002) is likely due to the constant switching between compatibility mappings in the present study. Importantly, this percentage was not modulated by experimental factors (all $F<0.80, p>0.38$ ). For the following analyses, "other" trials were discarded.

Distribution analysis. To reveal impulsive errors and partial errors, we conducted distribution analyses on the percentages of both overt as well as partial errors (van den Wildenberg et al., 2010). For both indices, the latency distributions of correct and error responses, or of correct and incorrect EMG onsets, were vincentized (Ratcliff, 1979) for each participant and each condition: after each distribution was rank-ordered and
Table 1. Global performance ${ }^{a}$

\begin{tabular}{llllllll}
\hline & \multicolumn{2}{l}{ Reaction time (ms) } & & & Errors (\%) & \\
\cline { 2 - 3 } & Compatible & Incompatible & I-C & & Compatible & Incompatible & I-C \\
\hline Sham & $402 \pm 20$ & $423 \pm 16$ & $21 \pm 8$ & & $5.8 \pm 1.3$ & $5.1 \pm 1.1$ & $-0.7 \pm 0.8$ \\
Cathode & $404 \pm 19$ & $426 \pm 15$ & $22 \pm 7$ & & $6.1 \pm 1.4$ & $4.2 \pm 0.8$ & $-1.9 \pm 1.1$ \\
Anode & $400 \pm 20$ & $420 \pm 16$ & $20 \pm 7$ & & $6.4 \pm 1.4$ & $5.1 \pm 1.1$ & $-1.3 \pm 1.2$
\end{tabular}

${ }^{a}$ Mean ( \pm SEM) reaction time of correct trials and error percentage for compatible and incompatible trials per tDCS condition. I-C (Incompatible minus compatible) represents the compatibility effect.

divided in seven quantiles (bins of equal number of trials), the mean (partial) error percentage was computed for each quantile. Mean data (across subjects) were obtained by averaging, quantile per quantile, the (partial) error rate and the latency determined individually, hence taking into account between-subjects latency differences. Mean (partial) error percentages for each quantile were plotted as a function of quantile latency. To investigate tDCS effect on response impulses, analyses focused on the first quantile (fastest overt and partial errors).

\section{Results}

\section{Global performance}

A classic compatibility effect was observed on mean reaction times $\left(F_{(1,17)}=9.70, p<0.01\right)$, whereas mean error rates were not significantly affected $\left(F_{(1,17)}=2.71, p=0.12\right)$. Neither reaction times nor error rates were affected by tDCS (both $F_{(2,34)}<$ $0.68, p>0.52)$, nor did they show any interaction between compatibility and tDCS (both $F_{(2,34)}<0.63, p>0.55$; Table 1). Hence, the modulation of SMC activity induced by tDCS did not affect subjects' global performance on the SRC task.

\section{Impulsive partial and overt errors}

Figure 2 shows the percentage of partial errors, i.e., subliminal incorrect EMG activity $(a)$ and overt errors ( $b$; i.e., when subjects actually gave the incorrect response) as a function of poststimulus time. Both partial and overt errors were most prominent shortly after stimulus onset (quantile effect on partial errors: $F_{(6,102)}=24.0, p<0.001$; on overt errors: $F_{(6,102)}=11.6, p<$ 0.001 ), and mainly for incompatible trials (interaction quantile ${ }^{*}$ compatibility on partial errors: $F_{(6,102)}=25.8, p<0.001$; on overt errors: $\left.F_{(6,102)}=7.23, p<0.001\right)$. To concentrate specifically on impulsive response activations, analyses were then focused on the fastest partial and overt errors.

Partial error analysis revealed that tDCS of the SMC did not affect the incidence of fast covert activations $\left(F_{(2,34)}=1.89, p=\right.$ $0.17)$. A compatibility effect showed up $\left(F_{(1,17)}=60.78, p<\right.$ $0.01)$, which did not interact with $\operatorname{tDCS}\left(F_{(2,34)}=0.14, p=0.87\right)$. The absence of a tDCS effect was further confirmed by planned orthogonal contrasts (compatibility conditions merged) verifying that neither cathodal nor anodal stimulation differed from sham (both $t_{(17)}<0.83, p>0.42$ ). Hence, covert impulsive action tendencies are comparable between all stimulation conditions.

In contrast, overt responses analysis revealed that SMC tDCS affected the occurrence of fast overt errors: a global tDCS effect was observed $\left(F_{(2,34)}=3.44, p<0.05\right)$, which did not interact with compatibility $\left(F_{(2,34)}=1.46, p=0.24\right)$. Planned orthogonal contrasts showed that accuracy was improved under cathodal stimulation compared with sham $\left(t_{(17)}=2.53, p<0.05\right)$, while anodal stimulation had no effect (anode vs sham, $t_{(17)}=0.37, p>$ 0.7). Crucially, the improved accuracy under cathodal stimulation could not be explained by a speed-accuracy trade-off as the mean latency of the fastest responses was not affected by tDCS ( sham, $306 \mathrm{~ms}$; cathode, $308 \mathrm{~ms}$; anode, $302 \mathrm{~ms} ; F_{(2,34)}=1.03$, $p=0.37$; cathode vs sham: $\left.t_{(17)}=0.42, p=0.68\right)$. Only a standard 


\section{a Partial Errors}
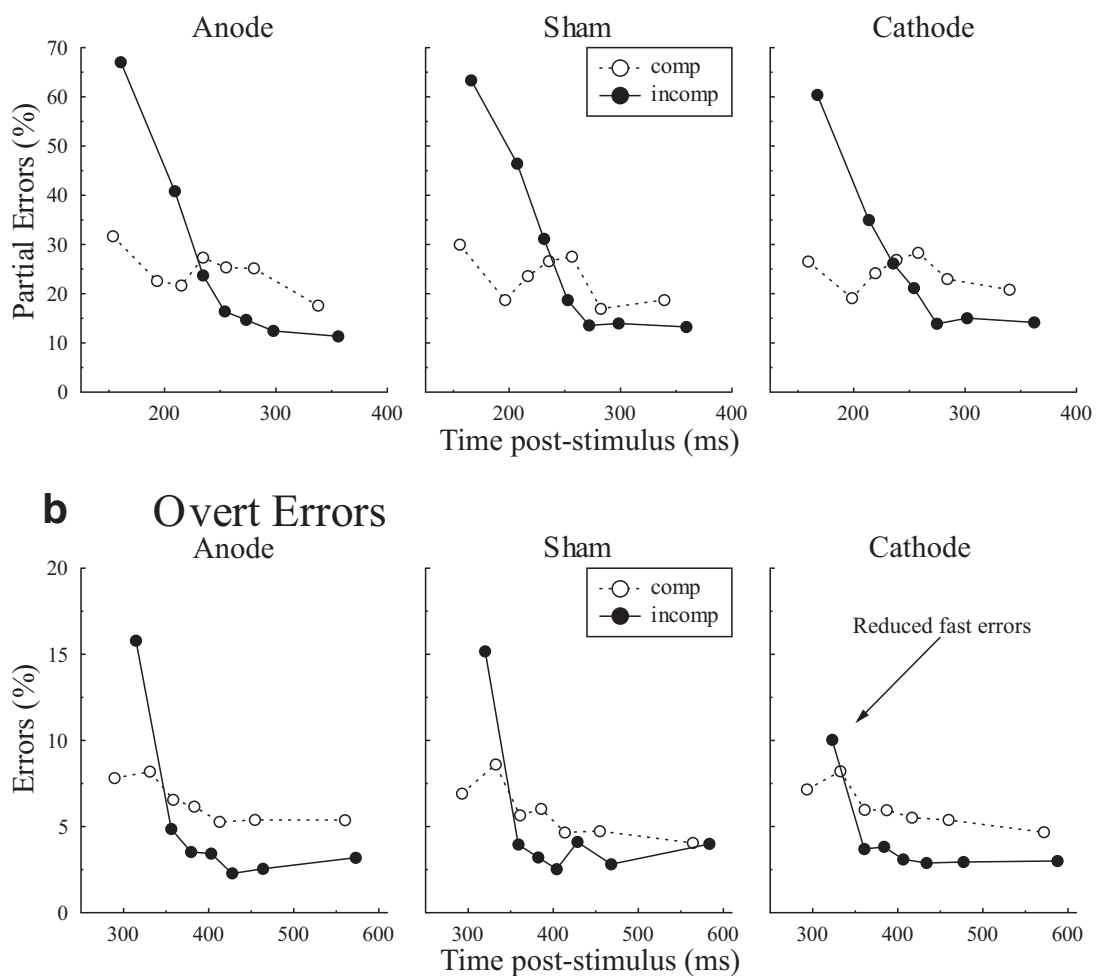

Figure 2. Partial and overt errors. $\boldsymbol{a}, \boldsymbol{b}$, Partial $(\boldsymbol{a})$ and overt $(\boldsymbol{b})$ error percentages as a function of poststimulus time for each tDCS condition (left, anode; middle, sham; right, cathode) for compatible (dotted white) and incompatible (solid black) trials.

compatibility effect was observed on the latency of overt errors (compatible, $292 \mathrm{~ms}$; incompatible, $319 \mathrm{~ms} ; F_{(1,17)}=46.81, p<$ $0.01)$.

\section{Motor processes}

To rule out possible motor execution effects, motor time (the time separating the correct EMG onset from the button press; Fig. $1 b)$, and correct EMG burst surface were analyzed. None were affected by tDCS (all $F<1.14, p>0.33$, including tDCS, compatibility, and tDCS $\times$ compatibility interaction). Also, no effect was observed on the partial error EMG surface (tDCS: $F_{(2,34)}=$ $2.10, p=0.14$; compatibility: $F_{(1,17)}=1.04, p=0.32$; $\mathrm{tDCS} \times$ compatibility interaction: $\left.F_{(2,34)}=1.15, p=0.33\right)$.

\section{Discussion}

Previous work evidenced the involvement of SMC, and more particularly its rostral part, the pre-SMA, in the control of response activation (Taylor et al., 2007; Forstmann et al., 2008b). However, it remains to be clarified whether such control is exerted by an a priori gating of impulsive response tendencies or through within-trial control of those impulses to prevent them from turning into overt errors. In the present study, we addressed this issue by combining advanced behavioral and EMG data analyses with electric stimulation of the SMC. This allowed us to dissociate the effects of SMC activity modulation on processes linked to covert response impulses from the processes associated to the within-trial control of those impulses: analysis of partial errors shows that the frequency and strength of fast response tendencies remained unaltered under SMC stimulation, whereas the analysis of overt errors shows a reduction of impulsive behavioral responses under cathodal stimulation. Hence, SMC does not prevent the emergence of stimulus-triggered response im- pulses, but keeps their overt behavioral expression in check. This demonstrates the critical role of the SMC in the withintrial control of response impulses and, as discussed below, provides essential cues that help in understanding the underlying physiological mechanisms. Whether those effects are mediated specifically by the rostral pre-SMA cannot be determined based on tDCS spatial resolution, as we cannot exclude the possibility that stimulation of neighboring areas also contributed to the effect (including, among others, the caudal SMA proper, but also premotor or the upper part of cingulate areas). Two different arguments, however, advocate that pre-SMA modulation drives the reported effects: first, tDCS electrodes were positioned so as to maximize pre-SMA stimulation, and second, a large body of literature (detailed below) supports the role of the pre-SMA in response control and response inhibition. We will hence consider that reported effects are to a large extent due to SMC stimulation, for which pre-SMA likely is here the key component.

Indeed, the present data nicely complement previous stimulation work showing the pre-SMA role in the control of response activations, either when the required response has to be inhibited after the sudden appearance of a countermanding stimulus, as in the case of the stop signal task (Chen et al., 2009; Hsu et al., 2011), or when an incorrect response has been activated by an incompatible stimulus (Taylor et al., 2007; Duque et al., 2013; Soutschek et al., 2013). The present data are also in line with studies showing correlations between pre-SMA activity or anatomical size with the control over inappropriate response activation (Forstmann et al., 2008b; van Gaal et al., 2011). None of those studies, however, could dissociate the a priori control of response activation from the on-line suppression of such activated responses. In the present study, investigating the effect of SMC activity modulation on covert response impulses revealed that fast covert activation of the incorrect response was still present, with similar magnitude, under cathodal, sham, and anodal stimulations. Thus, incorrect impulse activation was not affected by the modulation of SMC activity, contrary to impulsive overt responses, that were reduced under cathodal tDCS. This dissociation points to the role of SMC in controlling response activation impulses to avoid their behavioral expression, rather than in preventing them. This interpretation is consistent with Cai et al.'s (2012) results. They used variants of the stop signal task and observed that preSMA inactivation [induced by transcranial magnetic stimulation (TMS)] increased the stop signal reaction time, but did not influence the modulation of response tendencies.

In addition to helping us understand functional aspects of impulse control, the present data also provide useful information concerning the underlying physiological mechanisms. Prior knowledge about tDCS effects indicates that cathodal stimulation hyperpolarizes the underlying neurons (Nitsche et al., 2003; for review, see Nitsche et al., 2008), at least with the tDCS intensity and duration used in the present study (for evidence of an oppo- 
site effect with stronger intensities, see Batsikadze et al., 2013). The reduction of impulsive overt errors reported here hence presumably occurred when SMC neurons were hyperpolarized. Although this might be puzzling at first sight, we point out that hyperpolarization, while decreasing the area's excitability, does not necessarily lead to a functional inhibition. As a matter of fact, several studies showed that reduced excitability can be associated with increased efficiency of cortical processes. In the motor system, for instance, corticospinal excitability has been shown to decrease during motor preparation, presumably so as to increase signal-to-noise ratio and hence prevent erroneous premature responses (Davranche et al., 2007; Duque and Ivry, 2009). Additionally, behavioral improvement has also been reported when excitability is decreased artificially using stimulation techniques. For example, in perception, performance improvements in nearthreshold stimuli detection have been reported after cathodal stimulation, while anodal tDCS had no effect (Antal et al., 2004). The authors reasoned that tDCS-induced hyperpolarization improves performance by reducing sensitivity to neural noise. Finally, concerning the SMC, two recent studies that used repetitive TMS to decrease pre-SMA excitability reported performance improvement in both the stop signal task (Obeso et al., 2013) and a conflict task (Herz et al., 2014). As proposed in the sensory domain, excitability reduction in the motor system could increase efficiency (and hence improve performance) by reducing sensitivity to neural noise. Indeed, previous research established that pre-SMA activation disinhibits the motor cortex (Neubert et al., 2010) and inhibits the subthalamic nucleus (Jahfari et al., 2012), either directly or in association with the right inferior frontal gyrus (Herz et al., 2014), and this results in disinhibition of behavior. Likewise, pre-SMA activation resulting from instructions to emphasize speed over accuracy serves to upregulate activation in the dorsolateral striatum and to decrease response thresholds (as confirmed by quantitative evidence-accumulation modeling; Forstmann et al., 2008a). Here, cathodal tDCS hyperpolarized SMC neurons, which lowered their resting membrane potential and thus increasing the voltage difference between neurons' resting potential and their firing threshold (Bikson et al., 2004). Consequently, action impulses that would otherwise exceed the threshold (leading to overt errors) now remain below the threshold. Hyperpolarization, however, affects the activity of neurons in multiple ways (Bikson et al., 2004), and future research will help to clarify more precisely how it affects SMC functioning and outputs to the above-described network.

To conclude, the present results revealed that SMC is involved in preventing covert impulses from triggering overt responses rather than pre-empting such impulses. Interestingly, the reduction of impulsive errors occurred under SMC hyperpolarization, echoing the findings of previous studies that reported a behavioral improvement associated with a decreased excitability. We propose that excitability decrease might be one general mechanism that enables improved neural processing efficacy when the signal-to-noise ratio is low, e.g., in the motor domain, when involuntary actions can be easily triggered. In the present case, excitability reduction of SMC may prevent impulsive response activations from crossing the response threshold and thus trigger an impulsive error. The present results thus highlight a possible causal link between SMC activity and impulse control that clarifies the neurophysiology of impulsivity. These insights might help understanding individual differences in impulsivity and may point to new therapeutic avenues for clinical groups associated with impulse-related psychopathology.

\section{References}

Antal A, Nitsche MA, Kruse W, Kincses TZ, Hoffmann KP, Paulus W (2004) Direct current stimulation over V5 enhances visuomotor coordination by improving motion perception in humans. J Cogn Neurosci 16:521-527. CrossRef Medline

Batsikadze G, Moliadze V, Paulus W, Kuo MF, Nitsche MA (2013) Partially non-linear stimulation intensity-dependent effects of direct current stimulation on motor cortex excitability in humans. J Physiol 591:1987-2000. CrossRef Medline

Bikson M, Inoue M, Akiyama H, Deans JK, Fox JE, Miyakawa H, Jefferys JG (2004) Effects of uniform extracellular DC electric fields on excitability in rat hippocampal slices in vitro. J Physiol 557:175-190. CrossRef Medline

Burle B, Possamaï CA, Vidal F, Bonnet M, Hasbroucq T (2002) Executive control in the Simon effect: an electromyographic and distributional analysis. Psychol Res 66:324-336. CrossRef Medline

Cai W, George JS, Verbruggen F, Chambers CD, Aron AR (2012) The role of the right presupplementary motor area in stopping action: two studies with event-related transcranial magnetic stimulation. J Neurophysiol 108: 380-389. CrossRef Medline

Chamberlain SR, Sahakian BJ (2007) The neuropsychiatry of impulsivity. Curr Opin Psychiatry 20:255-261. Medline

Chen CY, Muggleton NG, Tzeng OJ, Hung DL, Juan CH (2009) Control of prepotent responses by the superior medial frontal cortex. Neuroimage 44:537-545. CrossRef Medline

Davranche K, Tandonnet C, Burle B, Meynier C, Vidal F, Hasbroucq T (2007) The dual nature of time preparation: neural activation and suppression revealed by transcranial magnetic stimulation of the motor cortex. Eur J Neurosci 25:3766-3774. CrossRef Medline

Duque J, Ivry RB (2009) Role of corticospinal suppression during motor preparation. Cereb Cortex 19:2013-2024. CrossRef Medline

Duque J, Olivier E, Rushworth M (2013) Top-down inhibitory control exerted by the medial frontal cortex during action selection under conflict. J Cogn Neurosci 25:1634-1648. CrossRef Medline

Fitts PM, Deininger RL (1954) S-R compatibility: correspondence among paired elements within stimulus and response codes. J Exp Psychol 48: 483-492. CrossRef Medline

Forstmann BU, van den Wildenberg WP, Ridderinkhof KR (2008a) Neural mechanisms, temporal dynamics, and individual differences in interference control. J Cogn Neurosci 20:1854-1865. CrossRef Medline

Forstmann BU, Dutilh G, Brown S, Neumann J, von Cramon DY, Ridderinkhof KR, Wagenmakers EJ (2008b) Striatum and pre-SMA facilitate decision-making under time pressure. Proc Natl Acad Sci U S A 105: 17538-17542. CrossRef Medline

Gandiga PC, Hummel FC, Cohen LG (2006) Transcranial DC stimulation (tDCS): a tool for double-blind sham-controlled clinical studies in brain stimulation. Clin Neurophysiol 117:845-850. CrossRef Medline

Herz DM, Christensen MS, Bruggemann N, Hulme OJ, Ridderinkhof KR, Madsen KH, Siebner HR (2014) Motivational tuning of frontosubthalamic connectivity facilitates control of action impulses. J Neurosci 34: 3210-3217. CrossRef Medline

Hsu TY, Tseng LY, Yu JX, Kuo WJ, Hung DL, Tzeng OJ, Walsh V, Muggleton NG, Juan CH (2011) Modulating inhibitory control with direct current stimulation of the superior medial frontal cortex. Neuroimage 56:22492257. CrossRef Medline

Jahfari S, Verbruggen F, Frank MJ, Waldorp LJ, Colzato L, Ridderinkhof KR, Forstmann BU (2012) How preparation changes the need for top-down control of the basal ganglia when inhibiting premature actions. J Neurosci 32:10870-10878. CrossRef Medline

Mars RB, Klein MC, Neubert FX, Olivier E, Buch ER, Boorman ED, Rushworth MF (2009) Short-latency influence of medial frontal cortex on primary motor cortex during action selection under conflict. J Neurosci 29:6926-6931. CrossRef Medline

Nachev P, Kennard C, Husain M (2008) Functional role of the supplementary and pre-supplementary motor areas. Nat Rev Neurosci 9:856-869. CrossRef Medline

Neubert FX, Mars RB, Buch ER, Olivier E, Rushworth MF (2010) Cortical and subcortical interactions during action reprogramming and their related white matter pathways. Proc Natl Acad Sci U S A 107:13240-13245. CrossRef Medline

Nitsche MA, Nitsche MS, Klein CC, Tergau F, Rothwell JC, Paulus W (2003) 
Level of action of cathodal DC polarisation induced inhibition of the human motor cortex. Clin Neurophysiol 114:600-604. CrossRef Medline Nitsche MA, Cohen LG, Wassermann EM, Priori A, Lang N, Antal A, Paulus W, Hummel F, Boggio PS, Fregni F, Pascual-Leone A (2008) Transcranial direct current stimulation: State of the art 2008. Brain Stimul 1:206223. CrossRef Medline

Obeso I, Cho SS, Antonelli F, Houle S, Jahanshahi M, Ko JH, Strafella AP (2013) Stimulation of the pre-SMA influences cerebral blood flow in frontal areas involved with inhibitory control of action. Brain Stimul 6:769-776. CrossRef Medline

Ratcliff R (1979) Group reaction time distributions and an analysis of distribution statistics. Psychol Bull 86:446-461. CrossRef Medline

Rushworth MF, Hadland KA, Paus T, Sipila PK (2002) Role of the human medial frontal cortex in task switching: a combined fMRI and TMS study. J Neurophysiol 87:2577-2592. Medline

Soutschek A, Taylor PC, Müller HJ, Schubert T (2013) Dissociable networks control conflict during perception and response selection: a transcranial magnetic stimulation study. J Neurosci 33:5647-5654. CrossRef Medline
Taylor PC, Nobre AC, Rushworth MF (2007) Subsecond changes in top down control exerted by human medial frontal cortex during conflict and action selection: a combined transcranial magnetic stimulation electroencephalography study. J Neurosci 27:11343-11353. CrossRef Medline

van Casteren M, Davis MH (2006) Mix, a program for pseudorandomization. Behav Res Methods 38:584-589. CrossRef Medline

van den Wildenberg WP, Wylie SA, Forstmann BU, Burle B, Hasbroucq T, Ridderinkhof KR (2010) To head or to heed? Beyond the surface of selective action inhibition: a review. Front Hum Neurosci 4:222. CrossRef Medline

van Gaal S, Scholte HS, Lamme VA, Fahrenfort JJ, Ridderinkhof KR (2011) Pre-SMA graymatter density predicts individual differences in action selection in the face of conscious and unconscious response conflict. J Cogn Neurosci 23:382-390. CrossRef Medline

Winer BJ (1971) Statistical principles in experimental design: design and analysis of factorial experiments. New York: McGraw-Hill. 